\title{
Cytogenetic variability in three species of the genus Cicindela (s.I.) (Coleoptera, Cicindelidae): Karyotypes and localization of 18S rDNA genes
}

\author{
Sónia J.R. Proença, Maria João Collares-Pereira and Artur R.M. Serrano \\ Universidade de Lisboa, Faculdade de Ciências, Centro de Biologia Ambiental, Campo Grande, \\ Lisboa, Portugal.
}

\begin{abstract}
Three tiger beetle species from the Cicindelini tribe were examined cytogenetically and found to have the following karyotypes: Cicindela argentata, $2 n=18+\mathrm{X}_{1} \mathrm{X}_{2} \mathrm{Y} / \mathrm{X}_{1} \mathrm{X}_{1} \mathrm{X}_{2} \mathrm{X}_{2}$; Cicindela aurulenta, $2 \mathrm{n}=18+\mathrm{X}_{1} \mathrm{X}_{2} \mathrm{X}_{3} \mathrm{Y}_{/} \mathrm{X}_{1} \mathrm{X}_{1} \mathrm{X}_{2} \mathrm{X}_{2} \mathrm{X}_{3} \mathrm{X}_{3}$ and Cicindela suturalis, $2 n=18+\mathrm{X}_{1} \mathrm{X}_{2} \mathrm{X}_{3} \mathrm{X}_{4} \mathrm{Y} / \mathrm{X}_{1} \mathrm{X}_{1} \mathrm{X}_{2} \mathrm{X}_{2} \mathrm{X}_{3} \mathrm{X}_{3} \mathrm{X}_{4} \mathrm{X}_{4}$. Fluorescence in situ hybridization (FISH) using a PCR-amplified 18S rDNA fragment as a probe showed the presence of ribosomal clusters in two autosomes in $C$. argentata, two autosomes and two heterosomes in $C$. aurulenta and in two heterosomes in $C$. suturalis (male configuration), revealing two new patterns of rDNA localization. Such results are representative of the cytogenetic variability observed in the species rich genus Cicindela (sensu lato) mainly as regards the localization of rDNA genes and the number and morphology of the heterosomes, in spite of the stability of autosome numbers. Changes in the localization and number of rDNA clusters were independent of changes in the number of sex chromosomes, indicating that several processes might have contributed to the great karyotypic diversity found within this speciose Coleopteran group.
\end{abstract}

Key words: chromosome evolution, Cicindela, multiple sex chromosomes, rDNA localization, tiger beetles.

Received: October 24, 2003; Accepted: May 5, 2004.

\section{Introduction}

The Coleopteran family Cicindelidae has about 2300 species distributed worldwide and is very successful in terms of species radiation (Cassola and Pearson, 2000; Pearson and Vogler, 2001). Several studies have been performed on the biology, ecology and geographical distribution of a great number of tiger beetle species (e.g. Pearson, 1988; Pearson and Vogler, 2001), although even so only about 80 species have until now been karyotyped (Serrano and Galián, 1998; Galián and Hudson, 1999; Galián et al., 2002; Proença et al., 2002a, b).

Tiger beetles have an unusually diverse karyotype, with a diploid chromosome number ranging from 12 to 44 and a great variety of both simple and multiple sex determination systems (Galián et al., 2002; Proença et al., 2002a, b). The most primitive tribes Manticorini, Omini and Megacephalini seem to be characterized by the presence of simple sex chromosome mechanisms of the X0 or XY types (Pearson and Vogler, 2001; Galián et al., 2002; Proença et al., 2002b). Multiple sex chromosome systems, XnY (where $\mathrm{n}$ varies from two to four) have been described in

Send correspondence to Maria João Collares-Pereira. Universidade de Lisboa, Faculdade de Ciências, Centro de Biologia Ambiental, Campo Grande, Edifício C2 - $3^{\circ}$ Piso, 1749-016 Lisboa, Portugal. E-mail address: mcolares@fc.ul.pt. the Cicindelini and Collyrini tribes and were considered an apomorphy of a large clade that includes these two tribes (Galian et al., 2002). These multiple heterosomes form a non-chiasmatic multivalent during meiosis linked by telomeric connections (Giers, 1977) and differ from other multiple sex systems described in Coleoptera (Serrano, 1980a, 1984; Galián et al., 1990a; 1996; Vitturi et al., 1996). Even so, a few species of Cicindelini have been described with simple sex chromosome mechanisms (see Giers, 1977; Serrano et al., 1986; Proença et al., 2002a), which were hypothesized to be a secondary condition.

The direction in which diploid chromosome numbers and distinct sex chromosome determination systems have changed during karyotype evolution in tiger beetles can be determined by phylogenetic and cytogenetic analyses (Vogler and Pearson, 1996; Galián and Hudson, 1999; Proença et al., 1999, 2002a, b; Galián et al., 2002). Apparently, there has been a reduction in the number of autosomal pairs from the most plesiomorphic groups to the most derived groups, with the genus Cicindela (s.l.) being stable and commonly having 9 to 10 chromosomes (Serrano and Galián, 1998) as well as non-chiasmatic multiple sex chromosome systems which presumably evolved from a simple chiasmatic system. 
Studies on the structure of the Cicindelidae genome have mainly been restricted to the in situ localization of the $18 \mathrm{~S}-28 \mathrm{~S}$ ribosomal gene clusters (rDNA) using fluorescence in situ hybridization (FISH). The data available show that basal groups have higher number of chromosomes bearing rDNA copies located exclusively on the autosomes (three and four pairs). In the most derived groups these numbers decrease to a minimum of one pair of rDNA clusters, which are located on the autosomes, heterosomes or both (Galián et al., 1995; Galián and Hudson, 1999; Pearson and Vogler, 2001, Proença et al., 2002a, b). Such a pattern of localization for these highly repetitive and conserved genes seems to follow the reduction in the number of autosomal pairs and may suggest rearrangements between heterosomes and autosomes which could be associated with changes in the number of sex chromosomes.

In this paper we present the first report on the karyotypes, sex chromosome systems and localization of major rDNA sites (using FISH) for three Cicindela (s.l.) species and also discuss the cytogenetic variability within the cicindelids.

\section{Material and Methods}

\section{Biological material}

Adult tiger beetles were collected from natural populations in the localities listed in Table 1. They were identified by one of the authors (A.R.M. Serrano) and were deposited at the Department of Animal Biology of the Faculty of Sciences, University of Lisbon, Portugal. The species studied were: Cicindela (Brasiella) argentata Fabricius, 1801, Cicindela (Cosmodela) aurulenta Fabricius, 1801 and Cicindela (Cylindera) suturalis Fabricius, 1798.

\section{Chromosome preparations}

Male and female gonads were dissected from ethyl-acetate anaesthetized adult beetles and then subjected to hypotonic treatment in distilled water and fixed using fresh ethanol-acetic acid solution (3:1) for one hour, with several changes of the fixative during the next day, the fixed gonads being kept at $-20{ }^{\circ} \mathrm{C}$ until needed. Small sections of the gonads were squashed in $70 \%$ acetic acid and the air-dried slides stained in phosphate buffered $4 \%$ Giemsa $(\mathrm{pH}=6.8)$ for karyotype analysis or kept in a $37^{\circ} \mathrm{C}$ incubator for at least three days before being subjected to FISH (Proença et al., 2002a).

\section{In situ hybridization}

FISH was carried out as described in Galián et al. (1999) with minor modifications. The hybridization probe used was obtained by amplification of an 18S rDNA fragment described in detail by De la Rúa et al. (1996) and labeled with biotin-16-dUTP by a second PCR reaction. The hybridization mixture contained $50 \%$ deionized formamide, $2 \mathrm{xSSC}, 50 \mathrm{mM}$ sodium phosphate $(\mathrm{pH}=7.0)$, $10 \%(\mathrm{w} / \mathrm{v})$ aqueous dextran sulfate and $4 \mathrm{ng} / \mu \mathrm{L}$ of biotin-labeled probe. Probe hybridization sites were detected by treatment with avidin-fluorescein isothiocyanate (FITC) and the signal amplified twice with goat anti-avidin-biotin (Vector). Slides were counter-stained with propidium iodide and examined under epifluorescence, images being captured with a DP-50 Olympus digital camera.

\section{Results}

The karyotypes of the three species were: $C$. argentata, $2 \mathrm{n}=18+\mathrm{X}_{1} \mathrm{X}_{2} \mathrm{Y} / \mathrm{X}_{1} \mathrm{X}_{1} \mathrm{X}_{2} \mathrm{X}_{2} ; C$. aurulenta, $2 \mathrm{n}=18+\mathrm{X}_{1} \mathrm{X}_{2} \mathrm{X}_{3} \mathrm{Y} / \mathrm{X}_{1} \mathrm{X}_{1} \mathrm{X}_{2} \mathrm{X}_{2} \mathrm{X}_{3} \mathrm{X}_{3}$; and $C$. suturalis, $2 \mathrm{n}=18+\mathrm{X}_{1} \mathrm{X}_{2} \mathrm{X}_{3} \mathrm{X}_{4} \mathrm{Y} / \mathrm{X}_{1} \mathrm{X}_{1} \mathrm{X}_{2} \mathrm{X}_{2} \mathrm{X}_{3} \mathrm{X}_{3} \mathrm{X}_{4} \mathrm{X}_{4}$ (Table 1).

We found that $C$. argentata had nine homomorphic pairs of metacentric and submetacentric chromosomes (Figure 1A). The Y chromosome was the smallest chromosome of the complement and the $\mathrm{X}_{1}$ and $\mathrm{X}_{2}$ chromosomes were medium-sized metacentrics. Female mitosis gave 22 chromosomes (Figure 1B), except for one female which had 23 chromosomes in about $80 \%$ of the mitotic metaphases analyzed, probably due to trisomy of autosomic pair 8. Diakinetic and metaphase II figures were not observed.

The autosomes of $C$. aurulenta were metacentric and submetacentric and gradually decreased in size (Figure $2 \mathrm{~A}$, $\mathrm{B})$. The $\mathrm{Y}$ was acrocentric and one of the biggest chromosomes of the set, while the $\mathrm{X}$ chromosome was among the smallest. Spermatocyte metaphase I cells were made up of nine rod- or ring-shaped bivalents plus a sex chromosome complex with four elements (Figure 2C). Spermatocyte metaphase II cells were of two types with $10(9+\mathrm{Y})$ and 12 $\left(9+X_{1} X_{2} X_{3}\right)$ chromosomes (Figure 2D).

Table 1 - Cytogenetic data and collection sites of the Cicindela species analyzed.

\begin{tabular}{llcclc}
\hline Species & $\begin{array}{c}\text { Number of specimens } \\
\text { sampled }\end{array}$ & $\begin{array}{c}\text { Number of mitotic } \\
\text { metaphases analyzed }\end{array}$ & 2n & Meioformula & rDNA localization \\
\hline Cicindela & 3 males & 6 & 21 & $9+\mathrm{X}_{1} \mathrm{X}_{2} \mathrm{Y}$ & Autosomes (2) \\
argentata & 4 females & 19 & 22 & $9+\mathrm{X}_{1} \mathrm{X}_{1} \mathrm{X}_{2} \mathrm{X}_{2}$ & Autosomes (2) \\
Cicindela & 2 males & 5 & 22 & $9+\mathrm{X}_{1} \mathrm{X}_{2} \mathrm{X}_{3} \mathrm{Y}$ & Autosomes (2), heterosomes (XX) \\
aurulenta & 3 females & 16 & 24 & $9+\mathrm{X}_{1} \mathrm{X}_{1} \mathrm{X}_{2} \mathrm{X}_{2} \mathrm{X}_{3} \mathrm{X}_{3}$ & Autosomes (2), heterosomes (XXXX) \\
Cicindela & 8 males & 14 & 23 & $9+\mathrm{X}_{1} \mathrm{X}_{2} \mathrm{X}_{3} \mathrm{X}_{4} \mathrm{Y}$ & Heterosomes $(\mathrm{XX})$ \\
suturalis & 8 females & 29 & 26 & $9+\mathrm{X}_{1} \mathrm{X}_{1} \mathrm{X}_{2} \mathrm{X}_{2} \mathrm{X}_{3} \mathrm{X}_{3} \mathrm{X}_{4} \mathrm{X}_{4}$ & Heterosomes $(\mathrm{XXXX})$ \\
\hline
\end{tabular}



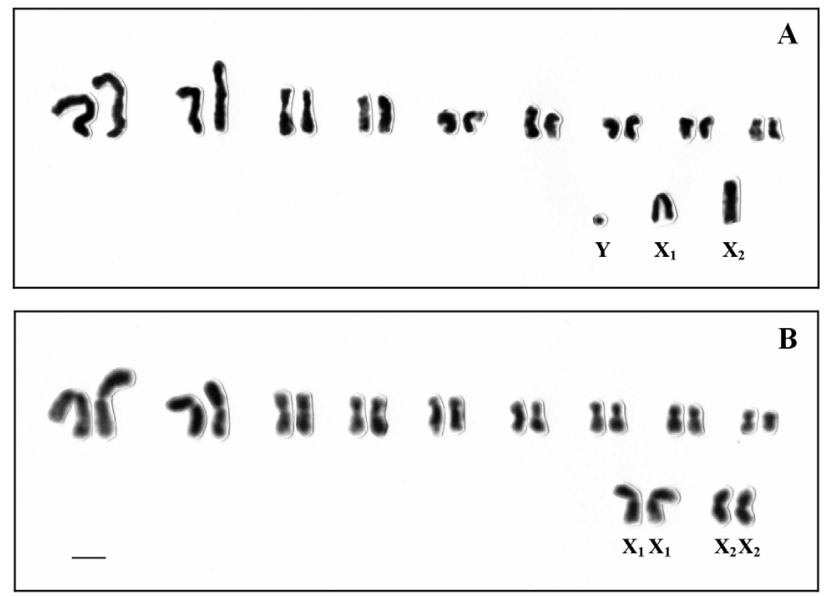

Figure 1 - Mitotic chromosomes of Cicindela argentata. (A) Male karyogram, $2 \mathrm{n}=18+\mathrm{X}_{1} \mathrm{X}_{2} \mathrm{Y}$; (B) Female karyogram, $2 \mathrm{n}=18+$ $\mathrm{X}_{1} \mathrm{X}_{1} \mathrm{X}_{2} \mathrm{X}_{2}$. Bars $=4 \mu \mathrm{m}$.
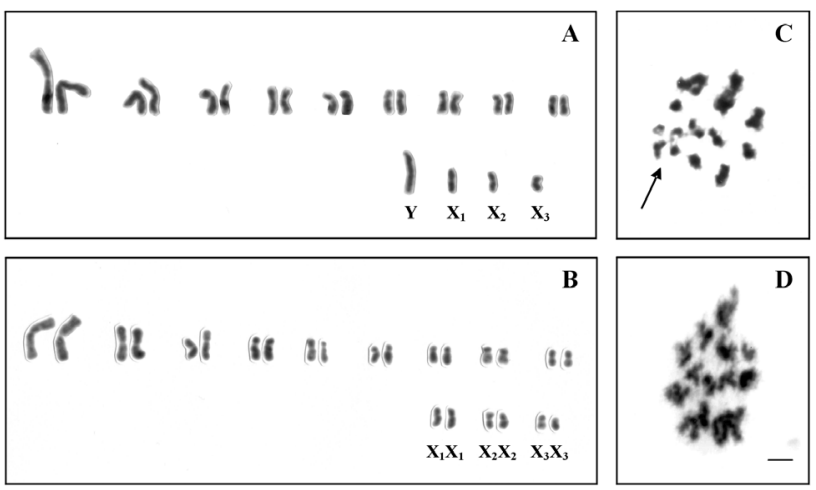

Figure 2 - Mitotic and meiotic chromosomes of Cicindela aurulenta. (A) Male karyogram, $2 \mathrm{n}=18+\mathrm{X}_{1} \mathrm{X}_{2} \mathrm{X}_{3} \mathrm{Y}$; (B) Female karyogram, $2 \mathrm{n}=18+$ $\mathrm{X}_{1} \mathrm{X}_{1} \mathrm{X}_{2} \mathrm{X}_{2} \mathrm{X}_{3} \mathrm{X}_{3} ;(\mathrm{C})$ male metaphase I and (D) male metaphase II, $\mathrm{n}=9+$ $\mathrm{X}_{1} \mathrm{X}_{2} \mathrm{X}_{3}$. Arrow indicates the multiple sex chromosomes. $\mathrm{Bar}=4 \mu \mathrm{m}$.

The chromosomes of $C$. suturalis gradually decreased in size with chromosome pairs 1,2 and 3 being metacentric and the remaining ones submetacentric. The heterosomes were among the smallest chromosomes of the complement, with the $\mathrm{X}_{1}$ chromosome larger than the $\mathrm{Y}$ chromosome (Figure 3A, B). Spermatocyte metaphase I cells had nine rod- or ring-shaped bivalents and a sex chromosome complex with five elements (Figure 3C). Spermatocyte metaphase II cells were of two types with 10 $(9+Y)\left(\right.$ Figure 3D) and $13\left(9+\mathrm{X}_{1} \mathrm{X}_{2} \mathrm{X}_{3} \mathrm{X}_{4}\right)($ Figure 3E) chromosomes.

In respect to the localization of rDNA sites, $C$. argentata showed two fluorescent signals on two medium-sized chromosomes (Figure 4A). FISH was not successful in male mitotic metaphases but hybridization of interphase nuclei showed fluorescent signals outside the sex vesicle, indicating rDNA clusters in the autosomes (not shown). Female mitotic plates of $C$. aurulenta had two small and four medium-sized labeled chromosomes (Figure
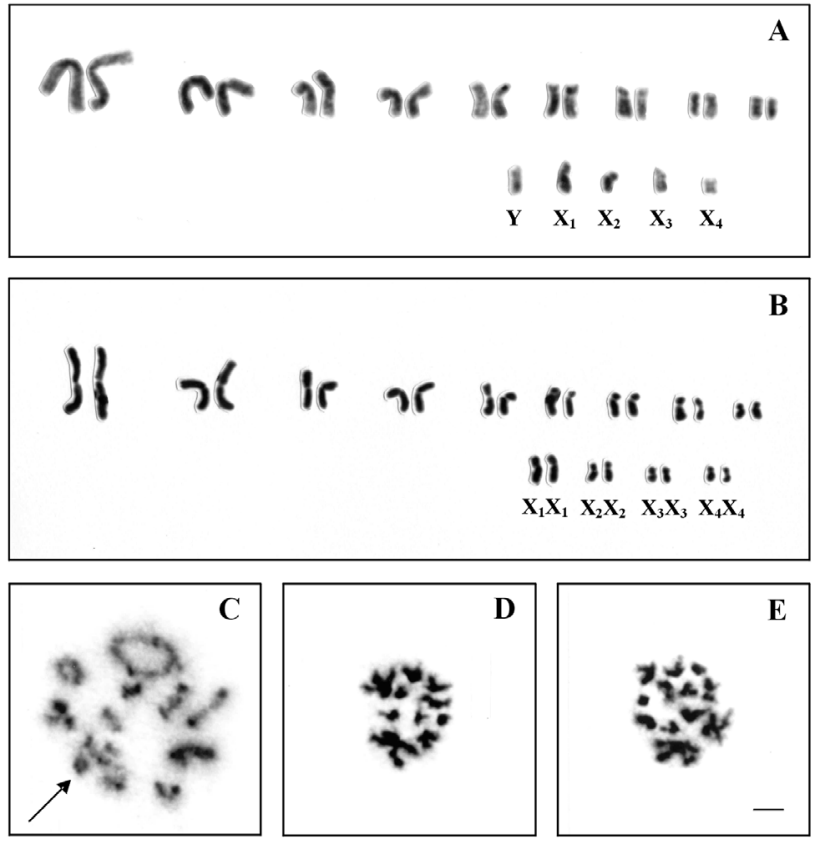

Figure 3 - Mitotic and meiotic chromosomes of Cicindela suturalis. (A) Male karyogram, $2 \mathrm{n}=18+\mathrm{X}_{1} \mathrm{X}_{2} \mathrm{X}_{3} \mathrm{X}_{4} \mathrm{Y}$; (B) Female karyogram, $2 \mathrm{n}=18+$ $\mathrm{X}_{1} \mathrm{X}_{1} \mathrm{X}_{2} \mathrm{X}_{2} \mathrm{X}_{3} \mathrm{X}_{3} \mathrm{X}_{4} \mathrm{X}_{4}$; (C) male metaphase I; (D) male metaphase II, $\mathrm{n}=9$ $+Y$ and (E) male metaphase II, $n=9+X_{1} X_{2} X_{3} X_{4}$. Arrow indicates the multiple sex chromosomes. $\mathrm{Bar}=4 \mu \mathrm{m}$.

4B). Meiotic plates showed two hybridization sites in an autosomal pair and two additional signals in the sex vesicle which seemed to correspond to two of the $\mathrm{X}$ chromosomes (Figure 4C). We also found that C. suturalis had four fluorescent-labeled small-sized chromosomes in the female mitotic chromosome complement (Figure 4D) and two small fluorescent-labeled chromosomes in the male mitotic plates (Figure 4E). Male metaphases I chromosomes showed two hybridization sites in the sex complex (Figure 4F), corresponding to two of the $\mathrm{X}$ chromosomes, probably the $\mathrm{X}_{3}$ and $\mathrm{X}_{4}$ chromosomes taking into account the size of the labeled chromosomes.

\section{Discussion}

The three species of Cicindelini revealed the presence of nine pairs of autosomes and multiple sex chromosome systems, although with different numbers of $\mathrm{X}$ chromosomes.

Although having some specific variations in their morphology, the autosomal pairs of the species studied share some common features, such as the mediocentric morphology of the chromosomes (meta- and submetacentric) and the existence of two large pairs of autosomes with the remaining chromosomes gradually decreasing in size. A similar pattern has also been described for the autosomes of other Paleartic, Indian and Australian Cicindela species (Serrano 1980b; Yadav and Karamjeet, 1981; Yadav et al., 1985; Serrano and Collares-Pereira, 

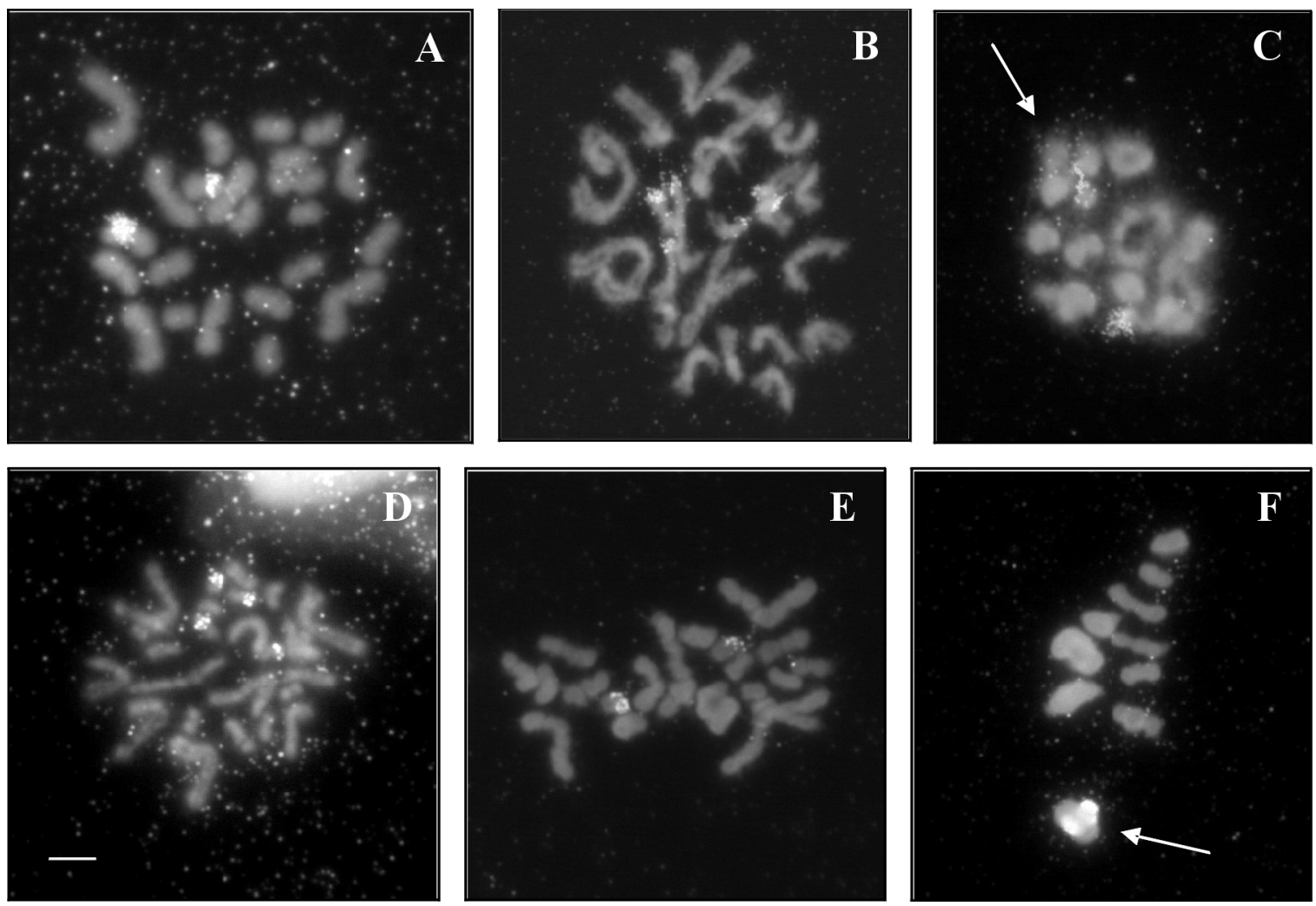

Figure 4 - Fluorescent in situ hybridization with a 18S rDNA probe of the chromosomes of the species of tiger beetles studied. (A) Cicindela argentata, female mitotic metaphase with two chromosomes labelled; (B) Cicindela aurulenta, female mitotic metaphase showing hybridization in six chromosomes; (C) C. aurulenta, male metaphase I with two signals in the sex complex plus two signals in one autosomal bivalent; (D) Cicindela suturalis, female mitotic metaphase showing four labeled chromosomes; (E) C. suturalis, male mitotic metaphase with fluorescence in two chromosomes; (F) C. suturalis, male metaphase I with two fluorescence signals in the sex complex. Arrows indicate the sex complex. Bar $=4 \mu \mathrm{m}$.

1989; Collares-Pereira and Serrano, 1990; Galián et al., 1990b; Yadav and Burra, 1991, 1994; Galián and Hudson, 1999). The heterosomes of the three species studied by us varied greatly in size, the $\mathrm{Y}$ chromosome being a small dot very difficult to identify in $C$. argentata but one of the biggest chromosomes in C. aurulenta. The $\mathrm{X}$ chromosomes were similar in size within each species but differed between species, being medium-sized in $C$. argentata but small in $C$. argentata and $C$. suturalis.

The karyotypes of $C$. argentata, $C$. aurulenta and $C$. suturalis can be used as an example of the three types of multiple sex chromosome systems found in the Cicindelini (2Xs, 3Xs and 4Xs), based on which several aspects related to the evolution of chromosomes within the family Cicindelidae can be discussed.

The generally accepted hypothesis for the development of the achiasmatic multiple sex chromosome systems in tiger beetles is that of a single-origin in a ancestor common to both Collyrinae and Cicindelini (Galián et al., 2002) before these two groups split. If we accept this single origin hypothesis, the multiple $\mathrm{X}$ system is remarkable within beetles because of its evolutionary antiquity (Galián et al., 2002). Phylogenetic and cytogenetic data support this hypothesis with the description of multiple sex chromosomes in Collyrini and Cicindelini but not in Megacephalini and in other basal groups (Sharma, 1988; Vogler and Pearson, 1996; Serrano and Galián, 1998; Galián and Hudson, 1999; Galián et al., 2002), with a few exceptions considered to be derived conditions. Also, the description of multiple sex chromosomes in the Cicindelini species (C. argentata, $C$. aurulenta and $C$. suturalis) discussed in this paper fits well into this pattern of chromosome evolution. The mechanisms underlying the development of such extraordinary multiple sex systems remain unknown, but several authors defended the theory of independent evolution of autosomes and heterosomes (Serrano and Collares-Pereira, 1989; Galián et al., 1990b) based on the following observations. In most of the Cicindela (s.l.) species so far described the number of autosomal pairs (9) remains unchanged while the number of heterosomes varies from two to four, as in the species now analyzed. Conversely, some African, Australian and Oriental Cicindelini species have 10,11 and 12 autosomal pairs and share the same number of heterosomes (Galián and Hudson, 1999; Proença et al., 1999). Moreover, the absence of chiasmata between the sex chromosomes may constitute a barrier for the translocation of chromosomal material between the chromosomes. 
In our research, the localization of major rDNA sites by FISH revealed different patterns for $C$. argentata, $C$. aurulenta and $C$. suturalis, with ribosomal clusters located in the autosomes, the heterosomes or in both. Different patterns regarding the localization of rDNA genes have been described in other Cicindela species : two clusters located in one autosomal pair (C. flexuosa, C. paludosa and $C$. hispanica); two clusters located in one autosomal pair and one in an X chromosome (C. littoralis and C. maura); two clusters located in one autosomal pair and two in the heterosomes (XY) (C. deserticoloides and C. circumdata) and three clusters located in the heterosomes (XXY) $(C$. trisignata) (see Proença et al., 2000; Proença and Galián, 2003). In our study we found two new rDNA localization patterns, i.e. the existence of copies of rDNA exclusively in two $\mathrm{X}$ chromosomes in $C$. suturalis and in one autosomal pair and in two Xs in C. aurulenta. The absence of descriptions of heterosomal copies located only on Y chromosomes may suggest that the heterosomal copies are functionally active and are also needed in females.

Basal groups of Cicindelidae exhibit the highest number of rDNA copies solely located on the autosomes, the number of copies ranging from three to four pairs (Galián and Hudson, 1999; Galián et al., 2002). The tendency for these genes to transfer from autosomes to heterosomes is seen from the most primitive cicindelid species to the derived cicindelid species, with subsequent diversification in the genus Cicindela (s.l.). Taking into account the apparent lack of interaction between the heterosomes and autosomes in the species with these multiple sex chromosome systems it has been suggested that the diversity of $18 \mathrm{~S}-28 \mathrm{~S}$ rDNA clusters in terms of localization could be due to non-genetic transposition mechanisms rather than simple translocations or other structural rearrangements. This was proposed by Mandrioli (2000) for the pufferfish Tetraodon fluviatilis where mariner-like transposable elements were found interspersed within the rDNA-associated heterochromatin. Such transposable elements have been considered to be responsible for a significant proportion of the observed karyotypic variation in many groups (revised in Kidwell, 2002) and mariner-like transposable elements have also been successfully amplified in some Cicindela species (S. Proença and J. Galián, unpublished results).

Future research on the genes located on the sex chromosomes (especially the Xs) and on the genetic control of sex determination and the evolutionary consequences of differential gene expression in males and females may provide insights into the patterns and processes of chromosome evolution in this speciose Coleopteran group.

\section{Acknowledgments}

This work was supported by grant number PRAXIS XXI/BD/15986/98 (Fundação para a Ciência e Tecnologia, Portugal) to SJRP. Thanks are due to José Galián for training in the FISH technique and Deodália Dias for allowing the use of PCR and in situ hybridization facilities. We also thank the Instituto Humbold (Colombia), Instituto de Ciências Naturales, Universidad Nacional de Colombia and Universidade Federal de Pernambuco, Brazil for field assistance in Colombia and Brazil. Rita Moura (Brazil) and A. Ali (Malaysia) are also kindly acknowledged for their help in collecting and sending material.

\section{References}

Cassola F and Pearson DL (2000) Global patterns of tiger beetle species richness (Coleoptera: Cicindelidae): Their use in conservation planning. Biol Conserv 95:197-208.

Collares-Pereira MJ and Serrano ARM (1990) Karyological analysis of Cylindera trisignata (Latreille \& Dejean, 1822) from Portugal (Coleoptera, Cicindelidae). Genetica 82:79-83.

De La Rúa P, Serrano J, Hewitt GM and Galián J (1996) Physical mapping of rDNA genes in the ground beetle Carabus and related genera (Coleoptera: Carabidae). J Zool Syst Evol Res 34:95-101.

Galián J, De la Rúa P, Serrano J, Juan C and Hewitt M (1999) Phylogenetic relationships in West Mediterranean Scaritina (Coleoptera, Carabidae) inferred from mitochondrial COI sequences and karyotype analysis. J Zool Syst Evol Res 37:85-92.

Galián J, Hogan JE and Vogler AP (2002) The origin of multiple sex chromosomes in tiger beetles. Mol Biol Evol 19 (10):1792-1796.

Galián J and Hudson P (1999) Cytogenetic analysis of Australian tiger beetles (Coleoptera: Cicindelidae): Chromosome number, sex-determining system and localization of rDNA genes. J Zool Syst Evol Res 37:1-6.

Galián J, Ortiz AS and Serrano J (1990a) Cytogenetics and cytotaxonomy of seven Iberian species of Brachinus Weber (Coleoptera, Carabidae). Cytobios 63:185-192.

Galián J, Ortiz AS and Serrano J (1990b) Karyotypes of nine species of Cicindelini and cytotaxonomic notes on Cicindelinae (Coleoptera, Carabidae). Genetica 82:17-24.

Galián J, Pruser F, De la Rua P, Serrano J and Mossakowski D (1996) Cytological and molecular differences in the Ceroglossus chilensis species complex (Coleoptera: Carabidae). Ann Zool Fenn 33:23-30.

Galián J, Serrano J, De la Rúa P, Petitpierre E and Juan C (1995) Localization and activity of rDNA genes in tiger beetles (Coleoptera: Cicindelinae). Heredity 74:524-530.

Giers E (1977) Die Nicht-Homologen-Assoziation multipler Geschlechtschromosomen in der Spermatogenese von Cicindela hybrida (Coleoptera). PhD Thesis, University of Münster, Germany.

Howell WM and Black DA (1980) Controlled silver-staining of nucleolus organizer regions with a protective colloidal developer: 1-step method. Experientia 36:1014.

Kidwell MG (2002) Transposable elements and the evolution of genome size in eukaryotes. Genetica 115:49-63.

Mandrioli M (2000) Mariner-like transposable elements are interspersed within the rDNA-associated heterochromatin of the pufferfish Tetraodon fluviatilis (Osteichthyes). Chromosome Res 8:177-179.

Pearson DL (1988) Biology of tiger beetles. Ann Rev Entomol 33:123-147. 
Pearson DL and Vogler AP (2001) Tiger Beetles. The evolution, Ecology and Diversity of the Cicindelids. Cornell University Press, Ithaca and London, $333 \mathrm{pp}$.

Proença SJR and Galián J (2003) Chromosome evolution in the genus Cicindela: Physical mapping and activity of rDNA loci in the tiger beetles species Cicindela littoralis and $C$. flexuosa. J Zool Syst Evol Res 41:227-232.

Proença SJR, Serrano ARM and Collares-Pereira MJ (1999) First record on the cytotaxonomy of cicindelids (Insecta, Coleoptera) from an Afrotropical region. Caryologia 52:37-47.

Proença SJR, Serrano ARM and Collares-Pereira MJ (2002a) Cytogenetic variability in genus Odontocheila (Coleoptera, Cicindelidae): Karyotypes, C-banding, NORs and localisation of ribosomal genes of $O$. confusa and $O$. nodicornis. Genetica 114:237-245.

Proença SJR, Serrano ARM and Collares-Pereira MJ (2002b) An unusual karyotype with low chromosome number in Megacephalini, a basal group of tiger beetles (Coleoptera, Cicindelidae): Cytogenetic characterisation by C-banding and location of rDNA genes. Hereditas 137:202-207.

Proença SJR, Serrano ARM and Galián J (2000) Patterns of rDNA localization in tiger beetles (Coleoptera: Cicindelidae). XXI International Congress of Entomology; Foz do Iguassu, Brazil (Abstract p 581).

Serrano ARM and Collares-Pereira MJ (1989) Cytotaxonomic study of Cephalota hispanica (Gory, 1833) and Spiralia maura (Linnaeus, 1758), two cicindelids from Portugal (Coleoptera). Genetica 79:69-75.

Serrano J (1980a) Scarites buparius, a caraboid beetles with an $\mathrm{X}_{1} \mathrm{X}_{2} \mathrm{Y}$ sex-chromosome system. Experientia 36:10421043.

Serrano J (1980b) Differencias cromosomicas entre Cicindela maroccana pseudomaroccana y C. campestris. Bol Asoc Esp Entomol 4:65-68.

Serrano J (1984) A chromosome study of Scarites occidentalis (Coleoptera, Caraboidea). Experientia 40:208-209.
Serrano J and Galián J (1998) A review of karyotypic evolution and phylogeny of carabid beetles (Coleoptera, Carabidae). In: Ball GE, Casale A and Vigna Taglianti A (eds) Phylogeny and Classification of Caraboidea. Mus Reg Sci Nat, Torino, pp 191-228.

Serrano J, Galián J and Ortiz A (1986) Cicindelid beetles without multiple sex chromosomes (Coleoptera, Caraboidea). Can J Genet Cytol 28:235-239.

Sharma PC (1988) Karyomorphology of three arboreal species of Indian tiger beetles (Coleoptera: Cicindelidae: Collyrinae) from Himal Pradesh. Proc Int Symp Recent Adv Cytogenet Res, Kurushetra, India (Abstract p 9).

Vitturi R, Catalano E, Sparacio I, Colomba MS and Morello A (1996) Multiple-chromosome sex systems in the darkling beetles Blaps gigas and Blaps gibba (Coleoptera, Tenebrionidae). Genetica 97:225-233.

Vogler AP and Pearson DL (1996) A molecular phylogeny of the tiger beetles (Cicindelidae): Congruence of mitochondrial and nuclear rDNA data sets. Mol Phylogenet Evol 6:321338.

Yadav JS and Burra MR (1991) Karyological investigations on Cylindera Westwood (Coleoptera: Cicindelidae). Elytron 5:177-188.

Yadav JS and Burra MR (1994) Karyological investigations on two species of cicindelid beetles (Coleoptera: Cicindelidae). Proc Conf Cytol Genet 4:113-116.

Yadav JS and Karamjeet K (1981) Chromosome studies on three species of Cicindelidae (Adephaga: Coleoptera) from Haryana. Zool Anz Jena 206:121-128.

Yadav JS, Kondal K and Yadav AS (1985) Cytology of Cicindela (Myriochile) undulata and C. (M.) fatidiosa with a summary of chromosomal data on the Cicindelidae. Cicindela 17:111 . 